have enabled MAFF to invest in rural enterprises to maintain employment in agriculture and related activities so as to promote conservation. The new clause is terribly weak, merely encouraging MAFF to further the cause of conservation but only within the narrow confines of their existing remit. The MacEwens are equally critical of the final shape of the Wildlife and Countryside Act with its inbuilt assumption that landowners are entitled to agricultural and forestry grants so that when such grants are denied on conservation grounds, the national park authorities will have to buy them out possibly to the tune of the profit foregone. They correctly emphasize that while these provisions are bad enough, the failure of the Act to cover the countryside outside the national parks and sites of special scientific interest could be disastrous. For here no notification is required of agricultural or forestry activity likely to be detrimental to conservation. It is hardly surprising that the agricultural community is anxious about its public image.

Like the Edinburgh group, the MacEwens conclude that the national park authorities are toothless watchdogs, that their record has been more one of cosmetics than conservation and that the maze of bureaucratic interests with a finger in the countryside pie is emasculating coordinated action. They argue for a unification of the Nature Conservancy Council and the Countryside Commission (and possibly, eventually, the Development Commission?) on the grounds that the distinction between conservation and landscape is an unnecessary one, which may well lead to a continual weakening of the conservation cause.

There is little doubt that in the wake of the passage of the Wildlife and Countryside Act, the national park idea, already under fire because of changing economic circumstances in remote rural areas, is even more under threat. The MacEwens' arguments should be taken seriously or the nation is in danger of losing something that it will find very difficult to replace.

Timothy O'Riordan is Professor of Environmental Sciences at the University of East Anglia. He is currently preparing the rural section of the UK response to the World Conservation Strategy.

\title{
The prosecution of syntax
}

\section{John C. Marshall}

To Mean - To Understand: Problems of Psychological Semantics. By H. Hörmann. Pp.337. ISBN 3-540-10448-8. (SpringerVerlag: 1981.) DM88, \$41.95.

MUCH of Professor Hörmann's latest book is taken up with attacks upon modern (that is, Chomskyan) linguistics and the psychological experimentation that has drawn upon Chomsky's ideas. Hörmann senses that the swings and roundabouts of outrageous fashion are deserting the paradigm that has dominated the field since 1957. "It is not uncommon", he writes, "that following a period of turbulent growth, a skeptical mood builds up and doubts begin to be expressed as to the rationale of progress achieved and the extent to which the position reached coincides with the original goals".

The particular malaise that Hörmann claims to detect has three main symptoms: current linguistic models are approaching "a level of complexity at which extreme sophistication borders on folly"; these models reveal a "widening gap between linguistic theory and the realities of language"; the last 25 years of work in linguistics and psycholinguistics has "contributed very little to a clarification of the problems of language use". Hörmann's antidote, as summarized in the last paragraph of the book, is that we should study how "the hearer is driven by the intentionality of his process of living-into-theworld", how "as he passes from one level to the next, the sounds, words, and sentences of the language become transparent" and "fade away to make room in his consciousness for the meaning meant"'.

I have no doubt that, sociologically, Hörmann's remarks are exactly to the point and that both his diagnosis and his remedy will strike a responsive chord in the breasts of many psychologists. Intellectually, however, the argument is more dubious. Consider first the charge of overcomplexity. No one would deny that, ceteris paribus, simple grammars should be preferred to intricate ones, but it is nature, not the linguist, that determines how elaborate the grammars of natural language are. And in any case, Hörmann seems unaware that a radical simplification of linguistic theory has taken place over the last decade; the proliferation of rules and rule-types that characterized generative syntax in the mid-1960s has been replaced by a system of very general principles whose interaction is responsible for the appearance of "phenotypic" diversity.

In order to appreciate the second complaint one must consider what "the realities of language", entail. For Hörmann,

human language is language because it is used by people for a purpose, namely, to live with other people. The purposeful use of language is embodied in acts of meaning and of understanding; in these acts the esse.:ce of language is integrated with the condition of man.

While the passage may be a trifle purple, the sentiments are surely unimpeachable. But why does Hörmann believe that gener- ative linguists have ignored "meaning" and "understanding"'? The central themes of Chomsky's work have always included the grammatical representation of thematic structure (who did what to whom with what), the referential possibilities of anaphoric elements, and the interpretation of the logical vocabulary of natural languages. There may be more to meaning than this, but surely these topics are part of "semantics" in anyone's story?

Hörmann's final point, that the study of language-use has not been advanced by recent psycholinguistic research, seems at first blush a particularly odd way of describing a period that has seen notable advances in modelling sentence parsing and production. Apparently, that area is not what Hörmann refers to as "languageuse". His fulminations are rather based upon the failure of generative linguistics and psycholinguistics "to predict events as they occur in everyday life". Hörmann's claim may be confidently conceded, although the complaint smacks of expecting Newton's laws of motion to predict when the last apple will fall from the tree in my back garden.

The bone of contention is this: common sense and Professor Hörmann know that there's a lot going on when two people talk with each other. In addition to speaking a common language (English, German, Malagassy, or whatever), the participants also bring to bear their tacit grasp of conversational maxims, and their vast knowledge of "the way the world is". Professor Hörmann notes, correctly, that theories of generative grammar do not explain everything about these "acts of meaning and understanding". But he then concludes that such theories therefore explain nothing. This hasty dismissal rather misses the point that however much extralinguistic factors may aid in understanding what someone really means, the greatest help surely comes from knowing the other person's language. It is precisely this knowledge that grammars explicate. The scope of formal grammars may, however, be very restricted. For example, Chomsky's position is that a particular level of linguistic representation - "the syntax of logical form" - is the interface between sentencegrammar and other faculties of mind implicated in the wider sense of the weasel word "semantics". Beyond the level of logical form no sharp dividing line is drawn between the "literal" meaning of a sentence and its interpretation in the light of the beliefs, knowledge and pragmatic inferences that can be brought to bear upon it. It is, of course, an empirical issue whether mental representations do indeed partition in this fashion. The pity is that Professor Hörmann obscures these topics by arguing that sentence-grammars fail to solve problems they were never intended to solve.

John C. Marshall is in the Neuropsychology Unit, part of the Neuroscience Group at the Radcliffe Infirmary, Oxford. 